\title{
EDUKASI SKRINING GIZI LANSIA UNTUK KADER POSYANDU LANSIA RW 011 KELURAHAN PENGGILINGAN
}

\author{
Rully Mujiastuti ${ }^{1}$, Erni Rita ${ }^{2}$, Sitti Nurbaya Ambo $^{3}$, Lily Herlina $^{4}$, Emi Susilowati $^{5}$, \\ Sugiartowo ${ }^{6}$ \\ 1,3,5,6 Teknik Informatika, Fakultas Teknik, Universitas Muhammadiyah Jakarta \\ ${ }^{2,4}$ Ilmu Keperawatan, Fakultas Ilmu Keperawatan, Universitas Muhammadiyah Jakarta \\ e-mail : rully@umj.ac.id
}

\begin{abstract}
Abstrak
Menjadi tua adalah sebuah fitrah perjalanan kehidupan tiap manusia. Banyak permasalahan yang terjadi pada seseorang yang menginjak lanjut usia, di antaranya terkait masalah yang berhubungan dengan gizi. Gizi seimbang menjadi salah satu bagian yang harus diperhatikan agar daya tahan tubuh lansia meningkat, penyakit berkurang dan semangat hidup meningkat. Demikian pula halnya dengan Posyandu Lansia Rw 011 Kelurahan Penggilingan yang menjadi mitra tim pengabdi. Posyandu ini memiliki jumlah lansia lebih dari 250 orang, sementara tingkat kehadiran lansia hanya sekitar 20\% saja. Kegiatan rutin Posyandu adalah kegiatan melakukan skrining kesehatan aktivitas sehari-hari dan risiko jatuh pada lansia, sementara untuk skrining gizi belum pernah dilakukan. Hal ini menjadi fokus tim pengabdi untuk melakukan edukasi kesehatan gizi lansia kepada kader posyandu lansia. Tujuannya adalah untuk meningkatkan jumlah skrining dan membentuk strategi intervensi kesehatan melalui aplikasi gizi LansiaSmart. Melalui kegiatan penyuluhan, pelatihan, pembinaan dan pendampingan ini, kader posyandu lansia lebih meningkat kapasitasnya. Skrining yang dilakukan bertambah, dari dua skrining menjadi tiga skrining dengan aplikasi skrining gizi LansiaSmart.
\end{abstract}

Kata kunci: Gizi, Kader Lansia, Lansia, LansiaSmart, Posyandu Lansia

\begin{abstract}
Getting old is a natural journey of every human being. Many problems occur in an elderly person, including problems related to nutrition. Balanced nutrition is one of the parts that must be considered in order to increase the body's resistance in the elderly, reduce disease and increase the spirit of life. Likewise with the Elderly Posyandu Rw 011 Penggilingan Kelurahan which is a partner of the service team. This Posyandu has more than 250 elderly people, while the attendance rate for the elderly is only around $20 \%$. Posyandu routine activities are activities to screen the health of daily activities and the risk of falling for the elderly, while nutrition screening has never been carried out. This is the focus of the service team to educate the elderly in nutrition health for elderly posyandu cadres. The aim is to increase the number of screenings and shape a health intervention strategy through the Elderly Smart nutrition application. Through outreach, training, coaching and mentoring activities, the capacity of the elderly posyandu cadres will increase. The number of screening performed increased, from two screenings to three screenings with the application of the Elderly Smart Nutrition screening application.
\end{abstract}

Keywords: Nutrition, Elderly Cadre, Elderly, Smart Elderly, Elderly Posyandu

\section{PENDAHULUAN}

Menurut UU No. 13 Tahun 1998, Lanjut Usia (lansia) adalah seseorang yang mencapai usia 60 tahun ke atas. Sementara, WHO mengatakan bahwa Lansia adalah pria dan wanita yang telah mencapai usia 60-74 tahun (Anon 2018a) . Pada usia ini, banyak terjadi penurunan fungsi organ, serta mengalami berbagai masalah kesehatan karena penyakit kronis maupun daya tahan tubuh yang menurun karena kurangnya asupan gizi. Karena itu, lansia membutuhkan bantuan dari sisi medis untuk meningkatkan status kesehatannya agar harapan hidup dapat meningkat. Puskesmas menjadi salah satu rujukan masyarakat dalam menjaga dan meningkatkan status kesehatan di usia lanjut termasuk pada wilayah Kecamatan Cakung di kotamadya Jakarta Timur. 
Salah satu program rutin yang ditangani adalah Puskesmas Kecamatan Cakung adalah program kesehatan lansia (Anon n.d., Anon n.d.). Setiap program lansia memiliki satu petugas khusus yang bertanggung jawab. Selain itu ada petugas lain untuk menjalankan pelayanan klinis yaitu dokter dan perawat. Empat Puskesmas yang berada di bawah wilayah Puskesmas (Pkm) Kecamatan Cakung yang sudah memiliki Poli Lansia adalah Pkm Kecamatan Cakung, Pkm Kelurahan Penggilingan 1 (Elok), Pkm Kelurahan Penggilingan 2 (PIK), dan Pkm Kelurahan Cakung Timur, sementara Pkm lainnya masih bergabung dengan Poli Umum. Untuk mendekatkan layanan kepada masyarakat, khususnya para Lansia, maka dibentuk Posyandu lansia yang berjumlah 89 Pos. Posyandu Lansia dikelola oleh masyarakat yaitu kader lansia yang saat ini berjumlah 579 orang. Kader Perempuan berjumlah 578 orang dan kader laki- laki 1 orang, untuk menangani 24.242 lansia sekecamatan Cakung. Salah satunya adalah Posyandu lansia yang berada di RW 011 Kelurahan Penggilingan. Kader Posyandu lansia di Rw 011 inilah yang menjadi mitra tim pengabdi.

Kegiatan Posyandu Lansia Rw 011 diselenggarakan satu kali dalam sebulan di pekan ketiga. Kegiatan rutin tersebut berupa : Senam lansia, Pendaftaran, Pengukuran berat badan dan tinggi badan, Pemeriksaan tensi darah, gula darah, asam urat dan kolesterol. Rata rata kehadiran lansia sekitar 50 orang dalam kegiatan Posyandu lansia tersebut. Sementara jumlah lansia yang terdata lebih dari 250 lansia dan perbandingan jumlah kader dengan lansia adalah 1: 36 , dengan total kehadiran sekitar 20\%. Dari hasil pemeriksaan diketahui bahwa mayoritas penyakit yang diderita adalah hipertensi, strooke serta diabetes. Adapun untuk pemeriksaan skrining kesehatan lansia dilaksanakan enam bulan sekali. Skrining tersebut berupa skrining aktivitas sehari-hari dan risiko jatuh lansia. Untuk skrining kesehatan gizi lansia belum dilaksanakan. Sehingga belum dapat diketahui berapa banyak lansia yang memiliki masalah malnutrisi, maupun penurunan daya tahan tubuh karena kurangnya asupan gizi.

Hasil dari wawancara dengan mitra dapat diketahui bahwa permasalahan utama ketidakhadiran lansia adalah; Pertama, tidak ada yang mendampingi untuk memeriksakan diri, sehingga mereka enggan untuk datang. Sementara kader sulit memberikan edukasi karena keterbatasan pengetahuan. Kedua, pada kegiatan rutin tidak diberikan obat, hanya mengecek tekanan darah dan pemeriksaan kadar gula darah serta asam urat, Ketiga, belum ada aplikasi skrining lansia yang memberikan gambaran awal kesehatan lansia. Skrining dilakukan enam bulan sekali untuk melihat kondisi aktivitas sehari-hari dan risiko jatuh pasien lansia. Sementara, skrining untuk ketahanan gizi yang terkait dengan malnutrisi belum ada. Keempat, bagaimana menyelesaikan permasalahan kesehatan dengan membentuk strategi intervensi kesehatan terhadap lansia, terutama dari sisi asupan gizi. Diperlukan sebuah upaya agar dapat meningkatkan harapan hidup lansia dengan meningkatkan daya tahan tubuhnya, terlebih dalam kondisi pandemi Covid 19 saat ini.

Program Kemitraan Masyarakat (PKM) ini mencoba memecahkan permasalahan ketiga dan keempat, yaitu meningkatkan gambaran kesehatan lansia melalui skrining gizi dan membentuk strategi intervensi kesehatan lansia. Tujuan Program Kemitraan Masyarakat (PKM) adalah untuk meningkatkan kapasitas kader Posyandu Lansia melalui edukasi kesehatan gizi lansia, melakukan sosialisasi skrining aplikasi LansiaSmart berbasis web untuk meningkatkan jumlah skrining yang akan memangkas waktu pengisian formulir manual serta mendapatkan rekomendasi hasil skrining. Untuk mencapai hal tersebut, maka tim pengabdi melakukan beberapa program kegiatan, yaitu penyuluhan, edukasi, pelatihan dan pembinaan kader dengan Gerakan Sayang Lansia.

Untuk implementasi skrining aplikasi LansiaSmart, diperlukan sebuah komputer atau hp dengan memori yang cukup untuk mengaktifkan aplikasi dan menginstallnya. Kemudian, mitra menginput data yang diperoleh dari hasil pemeriksaan ke dalam perangkat tersebut. Hasil skor yang diperoleh akan dihitung secara otomatis untuk dianalisis menjadi suatu rekomendasi untuk diberikan kepada lansia. Sementara permasalahan strategi intervensi kesehatan, dapat diawali dari tindak lanjut pemberian rekomendasi, misalnya dirawat di rumah atau dirujuk ke rumah sakit. Setelah itu dapat dilakukan penyuluhan, pelatihan, pembinaan, pendampingan dan implementasi aplikasi kepada petugas dan kader. 
Menurut (Mujiastuti et al. 2019) Lansia merupakan keadaan yang ditandai kegagalan mempertahankan kondisi stress secara fisiologis. Hal ini disebabkan oleh penurunan daya kemampuan untuk hidup dan peningkatan kepekaan individualnya. Untuk melaksanakan evaluasi multidimensial pada pasien lansia terdapat beberapa pemeriksaan. Menurut (Anon 2018b) adalah status fisik yang menunjukkan tanda vital, status fungsional yang menunjukkan kemandirian, status mental kognitif yang menunjukkan penurunan fungsi kognitif dan depresi, status nutrisi yang menunjukkan risiko terjadinya malnutrisi pada lansia dan status sosial ekonomi yang melibatkan keluarga, masyarakat sekitar dan lingkungannya. Status sosial yang baik menunjukkan status fungsional dan status kognitif yang masih baik.Adapun fokus pada program pengabdian masyarakat ini adalah pada instrumen MNA, tujuannya untuk mendeteksi status gizi lansia, sehingga akan mendapatkan rekomendasi lebih lanjut. Selain itu diharapkan ada kegiatan untuk memperkuat ketahanan gizi lansia sehingga dapat meningkatkan daya tahan tubuhnya, terutama dalam kondisi pandemi Covid 19 saat ini. Kegiatan untuk melakukan penapisan nutrisi menggunakan formulir Instrumen Mini Nutritional Assessment (MNA), yang telah disosialisasikan penggunaannya melalui aplikasi LansiaSmart hasil riset tim pengabdi.

\section{METODE}

Untuk merealisasikan kegiatan yang telah diuraikan di atas, maka tim pengabdi membuat tahapan atau langkah-langkah yang ditempuh guna melaksanakan solusi atas permasalahan yang dihadapi oleh mitra. Kegiatan Program Kemitraan Masyarakat ini akan dilakukan melalui tahapan berikut ini :

\section{Tahap 1 (Penyuluhan dan Sosialisasi)}

Pada tahap ini, mitra akan diberikan pengetahuan mengenai kondisi lansia, formulir skrining apa saja yang harus dilakukan untuk mengetahui kesehatan lansia dan cara melakukan skrining, bagaimana langkah rekomendasinya serta sosialiasi untuk menggunakan aplikasi skrining lansia untuk diterapkan pada Puskesmas maupun Posyandu Lansia). Kegiatan ini dilakukan untuk memberikan pemahaman awal mengenai metode skrining yang akan dilakukan.

2. Tahap 2 (Edukasi Strategi Intervensi Kesehatan Lansia)

Pada tahap ini, setelah hasil skrining diperoleh, mitra akan mendapatkan edukasi melalui penyuluhan mengenai strategi intervensi kesehatan lansia. Penyuluhan ini terkait dengan hal-hal berupa rekomendasi, tindak lanjut skrining, penyelesaian masalah jika terjadi kasus dan upaya pencapaian target skrining. Strategi ini dilakukan untuk menekan jumlah kasus lansia yang terjadi, misalnya dengan menambah posyandu sisipan, kunjungan petugas atau kader ke tempat lansia dengan ketergantungan berat dan total serta pembentukan Posyandu lansia yang baru dengan memberdayakan masyarakat sekitar.

3. Tahap 3 (Monitoring dan Pendampingan)

Tahap monitoring dan pendampingan dilakukan secara berkala dalam program ini. Hal ini untuk memastikan keberlanjutan program yang diterapkan oleh mitra. Selain itu dalam tahap monitoring ini, juga sebagai bahan masukkan dan analisis bagi tim pengabdi jika ditemukan permasalahan baru dalam implementasi program.

4. Tahap 4 (Evaluasi Pelaksanaan)

Tahap evaluasi pelaksanaan dilakukan dengan menggunakan diskusi tanya jawab maupun kuesioner untuk mendapatkan respon atau hasil dari pelaksanaan kegiatan abdimas ini

5. Tahap 5 (Pembuatan laporan dan publikasi)

Tahap akhir adalah dengan membuat laporan hasil adimas dan publikasinya 


\section{HASIL DAN PEMBAHASAN}

\section{A. Pelaksanaan Kegiatan Pengabdian Kepada Masyarakat (PKM)}

Pada kegiatan Pengabdian Kepada Masyarakat (PKM) kali ini, tema, waktu, lokasi pelaksanaan adalah sebagai berikut :

Tema : Edukasi dan Sosialisasi Penggunaan Skrining Kesehatan Untuk Kader Posyandu Lansia di Rw 011 Kelurahan Penggilingan Cakung Jakarta Timur

Tanggal: Senin, 3 Agustus 2020

Mitra :Posyandu Lansia di Kelurahan Penggilingan Cakung Jakarta Timur

Lokasi :Virtual atau Online atau Daring (Dalam Jaringan) melalui zoom meeting

Pendaftaran dan kuesioner dilakukan menggunakan google form melalui:

1. Pendaftaran Peserta:

https://bit.ly/FormPendaftaranPengmasUMJ

2. Daftar Hadir dan Kuesioner

https://bit.ly/DaftarHadirdanKuesionerPengmasUMJ

3.Jika sudah mengisi no. 1 dan 2, maka bisa unduh sertifikat https://bit.ly/SertifikatPengmasUMJ03082020

Flyer link pendaftaran program kegiatan PKM adalah sebagai berikut:

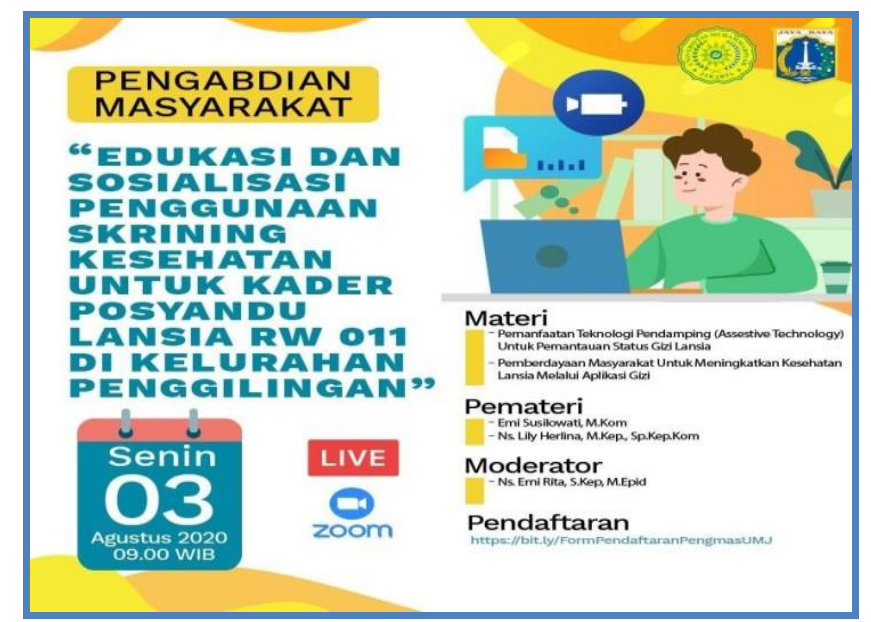

Gambar 1 Flyer link pendaftaran program kegiatan PKM

\section{B. Pencapaian Hasil Prosedur Kerja}

Tim Pengabdi telah melakukan beberapa kegiatan seperti yang direncanakan sebelumnya. Dalam pelaksanaan kegiatan, tim pengabdi melakukan koordinasi dengan para mitra. Adapun hasil yang dicapai dapat dilihat dalam tabel di bawah ini. 
Tabel 1. Pencapaian Hasil Prosedur Kerja

\begin{tabular}{|c|c|c|c|}
\hline No & Tahapan & Materi & Hasil \\
\hline 1 & Sosialisasi PKM & $\begin{array}{l}\text { - Brainstorming, alur dan tahapan } \\
\text { PKM }\end{array}$ & $\begin{array}{l}\text { - Mitra memberikan respon positif } \\
\text { dan menyetujui pelaksanaan PKM }\end{array}$ \\
\hline 2 & \begin{tabular}{|l|} 
Edukasi dan \\
sosialisasi aplikasi \\
teknologi informasi \\
dan materi edukasi \\
kesehatan lansia \\
secara Virtual \\
atau \\
Online atau Daring \\
(Dalam Jaringan)
\end{tabular} & $\begin{array}{l}\text { Materi Teknologi Informasi tentang } \\
\text { "Pemanfaatan Teknologi Pendamping } \\
\text { (Assestive Technology) Untuk } \\
\text { Pemantauan Status Gizi Lansia melalui } \\
\text { aplikasi LansiaSmart } \\
\text { Materi Edukasi Kesehatan tentang } \\
\text { "Pemberdayaan Masyarakat Untuk } \\
\text { Meningkatkan Kesehatan Lansia } \\
\text { Melalui Aplikasi Status Gizi Lansia }\end{array}$ & $\begin{array}{l}\text { - Kader posyandu lansia mendapatkan } \\
\text { pengetahuan baru mengenai aplikasi } \\
\text { gizi LansiaSmart } \\
\text { Kader posyandu lansia memperoleh } \\
\text { ilmu tentang gizi lansia, skrining gizi } \\
\text { menggunakan skrining MNA, } \\
\text { bagaimana tindak lanjut skrining. } \\
\text { - Selain itu, mitra mendapatkan } \\
\text { pengalaman dan ide pembentukan grup } \\
\text { lansia untuk yang memiliki penyakit } \\
\text { sejenis }\end{array}$ \\
\hline 3 & $\begin{array}{l}\text { Monitoring dan } \\
\text { pendampingan }\end{array}$ & $\begin{array}{l}\text { Tim pengabdi melakukan monitoring } \\
\text { terhadap kader posyandu lansia } \\
\text { secara online dan melakukan } \\
\text { pendampingan melalui grup Lansia } \\
\text { Werdha yang ada pada Posyandu } \\
\text { Lansia RW } 011\end{array}$ & $\begin{array}{l}\text { Konsultasi serta diskusi dan tanya } \\
\text { jawab dengan kader Posyandu } \\
\text { Lansia }\end{array}$ \\
\hline 4 & $\begin{array}{l}\text { Evaluasi } \\
\text { Pelaksanaan }\end{array}$ & $\begin{array}{l}\text { - Memberikan kuesioner kepada Mitra } \\
\text { terkait materi, pelaksanaan edukasi } \\
\text { dan sosialisasi sebagai bahan } \\
\text { evaluasi }\end{array}$ & $\begin{array}{l}\text { - Saran dan masukan dari Mitra untuk } \\
\text { Tim Pengabdi }\end{array}$ \\
\hline 5 & $\begin{array}{l}\text { Pembuatan } \\
\text { Laporan Akhir } \\
\text { dan Publikasi }\end{array}$ & $\begin{array}{l}\text { - Pembuatan laporan akhir } \\
\text { - Publikasi atas abdimas }\end{array}$ & $\begin{array}{l}\text { Laporan kegiatan abdimas dari } \\
\text { awal hingga akhir kegiatan } \\
\text { Publikasi kegiatan abdimas } \\
\text { melalui jurnal }\end{array}$ \\
\hline
\end{tabular}

\section{B. Luaran Pengabdian Kepada Masyarakat}

Berikut ini adalah bentuk luaran abdimas yang telah dilakukan oleh tim pengabdi.

\section{Aplikasi LansiaSMART}

Masalah gizi yang sering terjadi bagi usia lanjut ialah kekurangan gizi dan kekurangan berat badan. Bagi lanjut usia yang mengalami gangguan gizi diperlukan untuk penyembuhan dan mencegah agar tidak terjadi komplikasi pada penyakit yang dideritanya. Kurang gizi pada lansia dapat menyebabkan dampak yang lebih serius, seperti gangguan fungsi organ hingga risiko kematian.

Berdasarkan penjelasan di atas, maka pemenuhan gizi sangatlah penting bagi usia lanjut karena sangat berpengaruh untuk ketahanan tubuh. Hal ini menyebabkan adanya kebutuhan untuk membuat sistem informasi berupa Aplikasi Pemantauan dan Rekomendasi Status Gizi Lansia yang diberi nama "LansiaSMART.com" yang membantu Dokter dan Kader Posyandu Lansia dalam mengklasifikasi status gizi lansia serta memberikan rekomendasi kesehatan untuk Lansia secara real time. Berikut ini adalah contoh aplikasi "LansiaSMART.com" pada menu pemeriksaan dan rekam medis. 


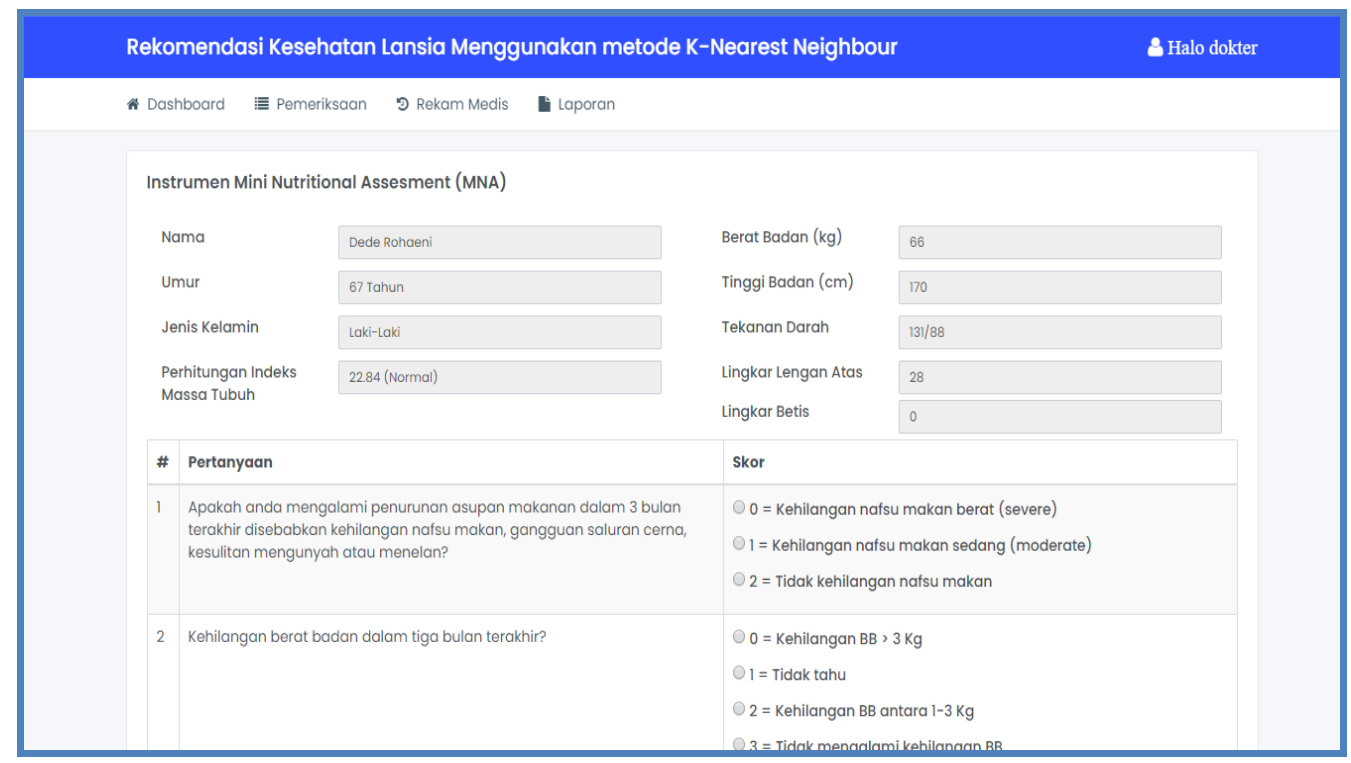

Gambar 2 Form Skrining Instrumen Mini Nutritional Assesment (MNA)

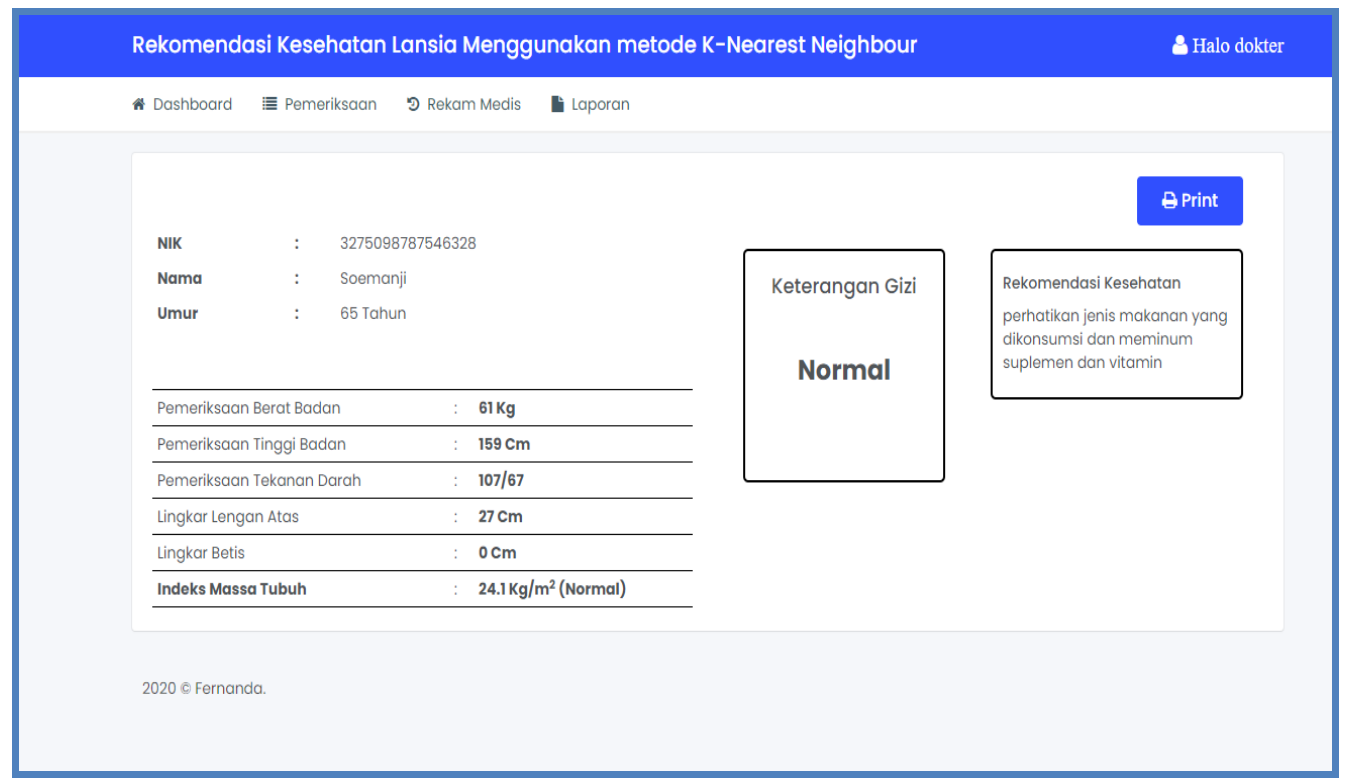

Gambar 3 Form Rekam Medis

\section{Materi Edukasi dan Sosialisasi}

Pada pengabdian ini, 2 materi disampaikan oleh pemateri yang berkaitan dengan materi pertama pemanfaatan teknologi pendamping (Assestive Technology) untuk pemantauan status gizi lansia dan materi kedua tentang pemberdayaan masyarakat untuk meningkatkan kesehatan lansia melalui aplikasi gizi.

Pada materi pertama diuraikan bagaimana dukungan teknologi komputer terhadap dunia kesehatan. Salah satunya adalah adanya aplikasi status gizi lansia yang menjadi skrining awal bagi seorang lansia, apakah menderita malnutrisi atau tidak. Setelah hasil skrining diketahui maka akan diberikan sebuah rekomendasi terhadap diri lansia tersebut melalui aplikasi yang digunakan.

Sementara pada materi kedua memaparkan bagaimana pemberdayaan masyarakat untuk meningkatkan kesehatan lansia yang dapat dilakukan melalui aplikasi gizi. Kader posyandu diberikan pemahaman mengenai perubahan fisiologis pada lansia yang mengakibatkan menurunnya kemampuan motorik untuk makan dan minum.Pengukuran status gizi lansia dilakukan dengan menggunakan skrining Mini Nutritional Assesment (MNA) dengan melihat Antropometri melalui pengukuran Berat Badan, Tinggi Badan, Indeks Masa Tubuh, Lingkar Lengan Atas (LILA). Setelah itu dilakukan pemeriksaan klinis melalui pemeriksaan fisik, dan 
pemeriksaan fungsional. Dari hasil riset didapati jumlah penderita malnutrisi pada lansia berjumlah $90 \%$ dari total 30 orang lansia.

3. Petunjuk Penggunaan Aplikasi "LansiaSMART.com"

"LansiaSMART.com" adalah aplikasi berbasis web yang berisi pemantauan dan rekomendasi status gizi Lansia yang dilakukan secara berkala oleh Dokter atau Kader Posyandu Lansia melalui pemeriksaan antropometri dan skrining Mini Nutritional Assesment (MNA) yang tersedia pada fitur aplikasi untuk mengetahui status gizi lansia dan pemberian rekomendasi kesehatan lansia. Pemberian kata SMART pada aplikasi "LansiaSMART.com" diambil pada singkatan Sehat, Mandiri dan Produktif. Halaman muka dari petunjuk penggunaan aplikasi "LansiaSMART.com" adalah sebagai berikut :

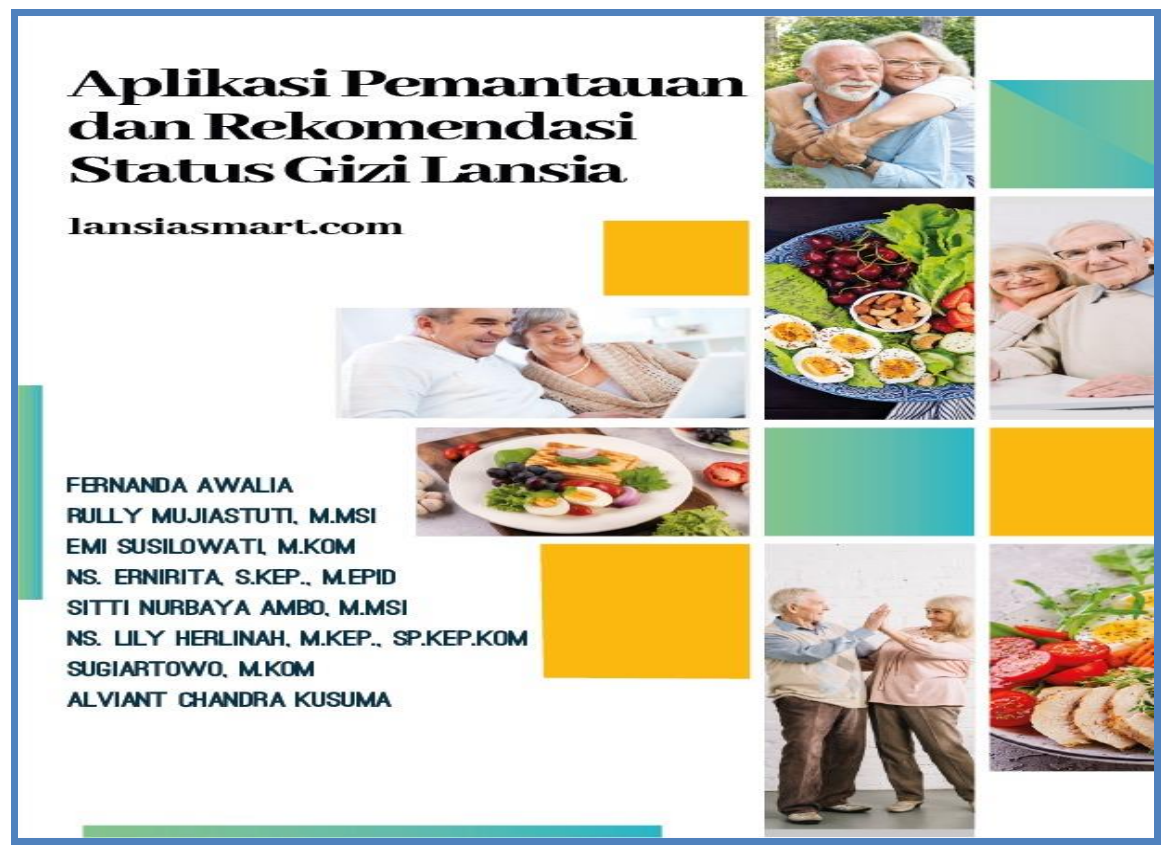

Gambar 4 Buku Panduan Aplikasi Skrining Gizi

Sementara gambar 5 berikut ini adalah saat pelaksanaan penyuluhan dan sosialisasi aplikasi gizi ke mitra Posyandu Lansia

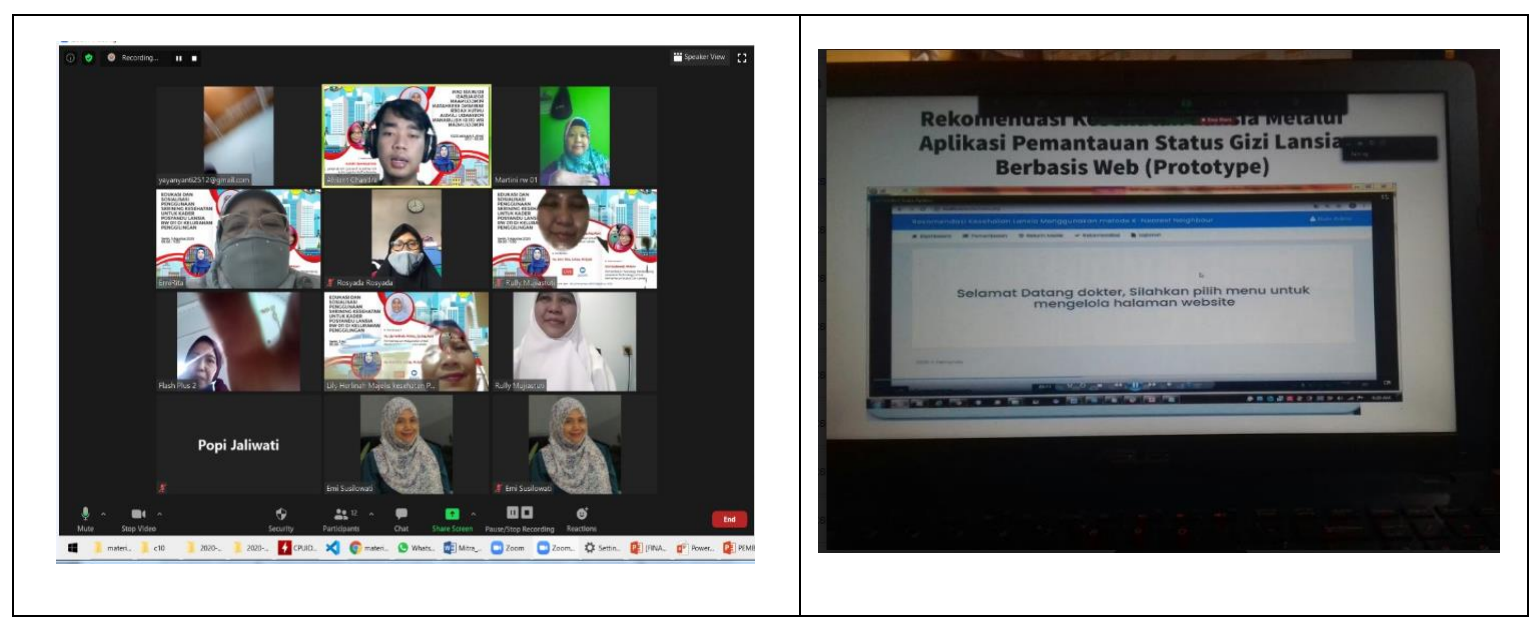




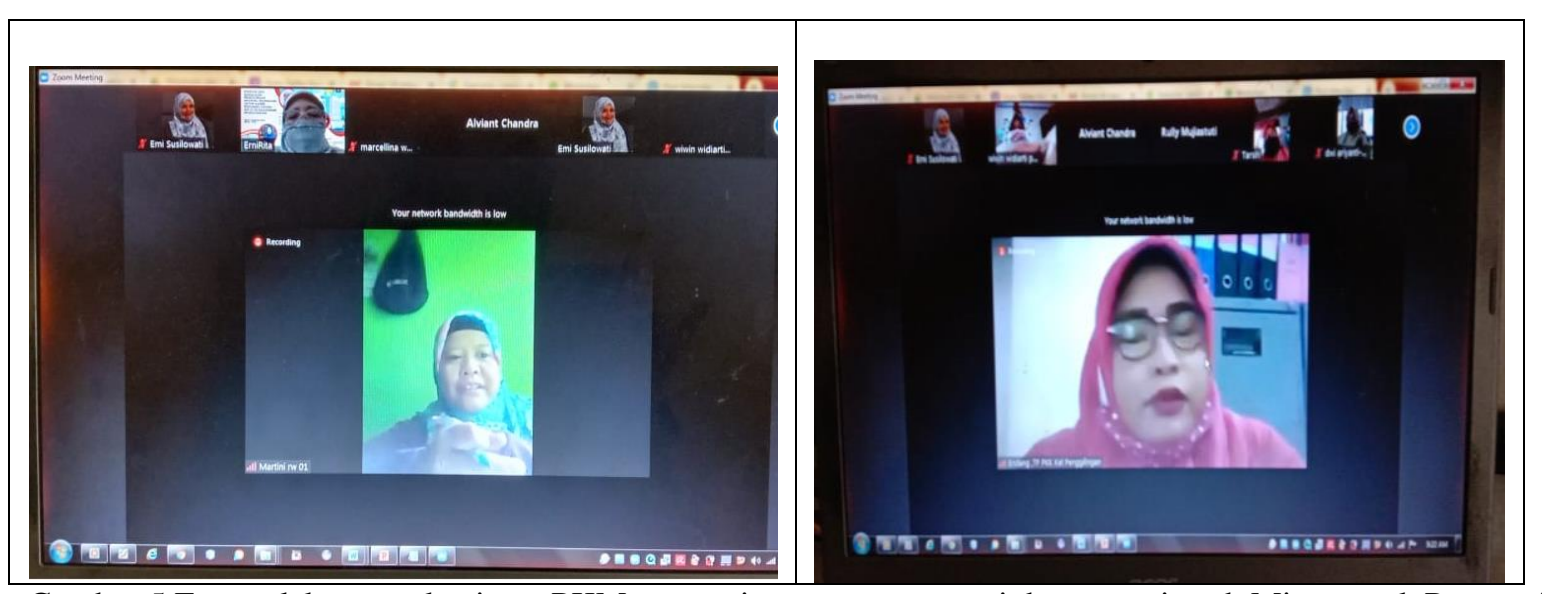

Gambar 5 Foto pelaksanaan kegiatan PKM saat sesi pemaparan materi dan tanya jawab Mitra untuk Pemateri

Pada saat diskusi antara tim pengabdi dan mitra dilakukan, permasalahan utama bagaimana meningkatkan kunjungan lansia ke posyandu pada saat sebelum pandemi, didapatkan solusi dengan menggunakan aplikasi skrining gizi lansia. Tim pengabdi juga memberikan sebuah usulan agar mita membentuk komunitas lansia untuk saling mendukung satu sama lain. Dengan komunitas ini, diharapkan agar lansia menjadi lebih bersemangat, dapat bertukar cerita, dan sehat. Sehingga, angka harapan hidup meningkat dan kualitas hidupnya lebih baik.

\section{SIMPULAN}

Melalui kegiatan PKM ini, tim pengabdi memberikan edukasi mengenai pemanfaatan teknologi pendamping (Assestive Technology) untuk pemantauan status gizi lansia dan edukasi pemberdayaan masyarakat untuk meningkatkan kesehatan lansia melalui aplikasi gizi. Kader Posyandu Lansia yang mengikuti, memahami permasalahan dan mendiskusikan solusinya dengan tim pengabdi. Kondisi malnutrisi yang terjadi pada lansia secara umum menjadi satu catatan tersendiri karena mencapai angka 90\% lebih. Adapun kendala teknis saat pelaksanaan edukasi pemanfaatan teknologi pendamping (Assestive Technology) untuk pemantauan status gizi lansia adalah masalah jaringan internet yang kurang stabil. Sehingga kualitas gambar dan suara kurang optimal. Namun, hal ini dapat diatasi dengan adanya diskusi dan tanya jawab lebih mendalam dengan mitra.Selain penerapan aplikasi gizi lansia, usulan pembentukan komunitas lansia juga menjadi salah solusi atas masalah yang dihadapi.

\section{SARAN}

Saran untuk kegiatan PKM lebih lanjut adalah dengan mengembangkan pemanfaatan aplikasi terintegrasi untuk Lansia. Aplikasi dibangun untuk melengkapi aplikasi pemantauan dan rekomendasi status gizi lansia.

\section{UCAPAN TERIMA KASIH}

Penulis mengucapkan terima kasih kepada Lembaga Penelitian dan Pengabdian Masyarakat Universitas Muhammadiyah Jakarta yang telah membiayai kegiatan ini.

\section{DAFTAR PUSTAKA}

Anon. 2018a. Profil Kesehatan Indonesia 2017. Kementerian Kesehatan - RI.

Anon. 2018b. PROFIL-KESEHATAN-DKI-JAKARTA-TAHUN-2017.Pdf. Dinas Kesehatan Provinsi DKI Jakarta.

Anon. n.d. "Cakung, Puskesmas Kecamatan | Portal Resmi Pemerintah Provinsi DKI Jakarta." Retrieved April 10, 2021 (https://jakarta.go.id/artikel/konten/470/cakung-puskesmaskecamatan).

Anon. n.d. "KECAMATAN CAKUNG: Jakarta Timur." Retrieved April 10, 2021 (https://lintasjaktim.blogspot.com/2010/11/kecamatan-cakung.html).

Mujiastuti, Rully, M. Ravi Mega Arasy, Rita Dewi Risanty, Hafita Ayuning, and Popy Meilina. 2019. "Aplikasi Status Pemeriksaan Activity of Daily Living (ADL) dan Risiko Jatuh Pasien Geriatri." P. 10 in. Fakultas Teknik, Universitas Muhammadiyah Jakarta: Fakultas Teknik, Universitas Muhammadiyah Jakarta. 